\title{
Fluent Speakers' Management of Prospective Communication Breakdowns: The Case of Stuttering
}

\author{
Stephanie Hughes (Corresponding author) \\ Department of Communication Disorders \\ Governors State University \\ 1 University Pkwy, University Park, IL 60484, USA \\ Tel: 1-708-534-4594 E-mail: shughes@govst.edu \\ Farzan Irani \\ Department of Communication Disorders \\ Texas State University - San Marcos \\ 601 University Drive, San Marcos, TX 78666, USA \\ Tel: 1-512-245-2330Ｅ-mail: firani@txstate.edu \\ Derek E. Daniels \\ Department of Communication Sciences and Disorders \\ Wayne State University \\ 207 Rackham Hall, Detroit, MI 48202, USA \\ Tel: 1-313-577-3339 E-mail: dedaniels@wayne.edu
}

Received: May 10, 2012

doi:10.5430/elr.v1n1p35
Accepted: May 23, 2012

Online Published: June 5, 2012

\begin{abstract}
Stuttering is a disorder of verbal fluency that is often associated with such negative stereotypes as shyness and anxiety. This study investigates typically fluent speakers' advice to both people who stutter (PWS) and other fluent speakers as they interact with each other. A written, open-ended, qualitative survey was administered to 135 members of the general public and analyzed thematically. Results indicate that stuttering is a disorder that engenders cognitive and emotional reactions in fluent speakers as well as proscribed communication strategies designed to prevent and manage communicative breakdowns. Fluent speakers appear to engage in high-level metalinguistic and metacognitive strategies as they interact with someone who stutters and believe that PWS should do the same. Research implications for those who work with people who have communication disorders in educational and healthcare settings are discussed.
\end{abstract}

Keywords: Stuttering, Communication disorders, Communication strategies

\section{Introduction}

Stuttering, also known as stammering, is a disorder of verbal communication that affects approximately $1 \%$ of the world's population (Bloodstein \& Bernstein Ratner, 2007). While typically fluent speakers can produce up to 230 words per minute with relative ease, the speech of people who stutter (PWS) is often fraught with repetitions, hesitations, and stoppages in speech production (Guitar, 2006). The exact cause of stuttering is unknown, but it is believed that stuttering is caused by both genetic and environmental factors that make it difficult for PWS to coordinate their respiration, phonation, and articulation at the neurological level (Perkins, Kent, \& Curlee, 1991). Developmental stuttering begins in childhood, usually before age five (Yairi \& Ambrose, 2005). Most children who do not grow out of their stuttering and have a chronic stuttering problem in adulthood develop coping mechanisms to try to be more fluent and hide their stuttering. These coping mechanisms, referred to as secondary behaviors, are 
often more distracting than the stuttering itself and can include muscle tension, distracting limb movements, excessive use of fillers such as "um" and "you know," and avoidance of verbal communication in social, academic, and occupational situations (Guitar, 2006). Maladaptive secondary behaviors may be worsened as PWS struggle to appear more fluent in front of fluent speakers who may present negative attitudes toward stuttering and PWS.

Unfortunately, decades of research have indicated that fluent speakers do hold negative attitudes toward stuttering and PWS. In a survey of the general population, Ham (1990) found that more than one-third of participants believed that PWS are psychologically different from fluent speakers and described PWS as being shy, frustrated, and anxious. These stereotypes about PWS have persisted despite little evidence to support their accuracy (Bennett, 2006). These findings suggest that stuttering is not well understood by the general public. Studies involving speech-language pathologists (Kalinowski, Armson, Stuart, \& Lerman, 1993) and educators (Lass et al., 1992) have also indicated that these professionals may also hold some negative stereotypes of PWS, though recent evidence suggests these attitudes may be changing in a more positive direction (Swartz, Gabel, \& Irani, 2009). In general, however, many variables are not good predictors of attitudes toward stuttering, including one's gender, age, years of education, personally knowing someone who stutters, and knowledge of stuttering (Hulit \& Wirtz, 1994). The generally negative and narrow range of opinions toward stuttering and PWS as measured quantitatively through questionnaires and semantic differential scales has led to a call for innovative methods which allow new insights into the attitudes of fluent speakers toward stuttering and PWS (Hulit \& Wirtz, 1994).

Some researchers have heeded this call and have engaged fluent speakers in tasks that can better explain the reactions of fluent speakers toward stuttering. For example, Panico, Healey, Brouwer, and Susca (2005) assessed the degree to which stuttering severity influenced fluent speakers' perceptions of PWS. The results indicated that as stuttering severity increased, so too did listeners' negative ratings and comments about the speaker who stuttered. Listener effort and impatience increased as stuttering severity increased, while listener comfort decreased. This finding was confirmed by researchers who collected heart rate and skin conductance (palm sweat) measures as fluent speakers watched videos of PWS (Guntupalli, Kalinowski, Nanjundeswaran, Saltuklaroglu, \& Everhart, 2006). Fluent speakers tended to have a slower heart rate when listening to PWS, indicating that listeners pay more attention to the speech of PWS than that of fluent speakers. Increased skin conductance was also noted when fluent speakers watched videos of PWS, suggesting that listeners experience unpleasant emotional arousal when listening to stuttering.

Thus, it is readily apparent that fluent speakers have a heavier cognitive and emotional load when interacting with someone who stutters than with other fluent speakers. A small number of studies have attempted to address why a persistent negative stereotype has developed toward PWS. White and Collins (1984) posited that PWS appear nervous, shy, and otherwise neurotic to fluent speakers because chronic stuttering mimics, on a superficial level, the typical disfluencies that fluent speakers have when in anxiety-provoking situations, like public speaking. Hughes, Gabel, Irani, and Schlagheck (2010a) found that fluent speakers may hold simultaneously positive and negative attitudes toward PWS. For example, fluent speakers tend to believe that PWS are likeable individuals who are poor communicators, a combination of perceived high-warmth and low-competence that elicits pity and passive harm from listeners according to social psychologists (Cuddy, Fiske, \& Glick, 2008).

Another source of negative attitudes toward PWS may be the uncertainty that fluent speakers feel as they converse with someone who stutters. Hughes, Gabel, and Irani (2010b) conducted a study in which university students were asked to complete an open-ended questionnaire about how fluent speakers and PWS can help each other when engaging in conversation. The results indicated that fluent speakers do not wish to offend PWS but are uncertain of how to act around them. For example, is it appropriate to fill in words or complete sentences for someone who stutters? Should one ask close-ended questions to minimize the communicative load for PWS? Do PWS appreciate it when someone speaks for them so they don't have to? Hughes et al. (2010b) concluded that while the overall tone of the responses was positive and fluent speakers believe PWS deserve kindness and respect, fluent speakers are also likely to engage in behaviors which might lead to disempowerment of PWS.

A limitation of the Hughes et al. (2010b) study was the need for a sample of participants that did not consist only of university students. It is not clear at the present time if older adults hold the same beliefs toward PWS as students in their teens and early twenties. Thus, the current study replicates that of Hughes et al. with the general population in order to investigate: (a) communicative strategies advocated by members of the general public as they consider conversing with PWS, and (b) the nature of these strategies and how they are rationalized by fluent speakers. The overarching goal of the study is to provide a deeper understanding of how fluent speakers believe they should modify 
their communication patterns when conversing with PWS, and the implications of these modifications for scholarly research and professional practice in this area.

\section{Methods}

\subsection{Design}

A phenomenological qualitative research design was implemented. This design is a process of inquiry in which researchers explore social or human issues in order to gain an in-depth understanding of the subjective experiences of people who have experienced these issues (Creswell, 2007). Qualitative researchers explore, in detail, how participants in a study perceive or experience a particular phenomenon, such as how fluent speakers believe they should interact with PWS. It should be noted that qualitative research methods are fundamentally different than quantitative paradigms, as they sacrifice rigid experimental controls, quantifiable data, and statistical analysis for a deep understanding of the issues at hand (Maxwell, 2005). Qualitative research methods were necessary for this study in order to conduct an in-depth exploration of fluent speakers' beliefs about interactions with PWS.

\subsection{Participants}

A total of 135 members of the general public served as participants. Graduate students in a communication disorders program in the United States recruited their friends, family, and co-workers to take an online survey via email. Exclusionary criteria included being less than 18 years old and being a college student or speech-language pathologist (as data related to college students and speech-language pathologists had already been collected for similar studies). Each email invitation was individualized (i.e., no group emails or links to the survey on students' social media sites) and reminder notices were sent approximately one week after the initial survey invitation was sent. The response rate was $96.4 \%$.

The average age of participants was 39.5 years with a range of $18-73$ years. Women accounted for $56.5 \%$ of the sample and men $43.5 \%$. The occupations of participants were mostly from industrial, administrative, and healthcare sectors. Most participants (55.7\%) had completed a 4-year university degree. The majority of participants were white/Caucasian (94.6\%), with Hispanic participants constituting the largest minority group represented in the sample (4.6\%).

Participants varied in terms of their familiarity with PWS and ranged from knowing no one who stutters to knowing more than six PWS. Twenty-five percent of participants reported not knowing anyone who stutters. Nineteen participants reported having a history of a speech, language, or hearing disorder. Of these participants, four reported having a history of stuttering and were removed from the data set.

\subsection{Survey}

A modified version of the survey used in the Hughes et al. (2010b) study was administered to participants using an online surveying tool. The survey consisted of a demographic questionnaire that asked participants to provide such information as their age, gender, ethnicity, and occupation. Participants were also asked to indicate whether they had a history of a communication disorder, and if so, if that disorder was stuttering. In addition, participants were asked if they knew someone who stutters, and if so, how well they knew that person. The second part of the survey consisted of two open-ended questions. The first question asked, "What, if anything, can people who stutter do to help facilitate conversations between people who stutter and people who do not stutter?" The second question was similar and asked "What, if anything, can people who do not stutter do to help facilitate conversations between people who stutter and people who do not stutter?" The instructions presented to respondents indicated that open and honest answers were appreciated, and that there were no right or wrong answers. Participants were also given a basic definition of stuttering prior to beginning the survey and were informed that they did not need to know anything about stuttering or anyone who stutters to complete the survey.

\subsection{Data Analysis}

Participants' responses were arranged in a Microsoft Excel spreadsheet and subsequently analyzed according to the guidelines for qualitative research as proposed by Maxwell (2005). In the first step in the analysis process, the first and second authors independently read over the data and took notes regarding initial impressions. Preliminary ideas about the nature of participants' attitudes and how their responses could be categorized and organized were developed. This process, called coding, was used to develop relationships among participants' statements that allowed for comparisons of the data. Agreement between the first and second author on the codes and how they were to be applied to participants' statements was then established. Themes, or meaningful units, were subsequently developed by grouping similar codes, thus allowing the authors to present the broader issues that were representative 
of participants' individual responses (Maxwell, 2005). To further ensure credibility, an independent reviewer (the third author, who has expertise in both stuttering and qualitative research methods) validated the themes.

\section{Results}

Analysis of both open-ended survey items (i.e., how PWS can help fluent speakers in conversation and how fluent speakers can help PWS) was conducted separately; however, the results of the thematic analysis indicated a large overlap in the advice participants gave to both fluent speakers and PWS as they converse with each other. Thus, rather than presenting separate, repetitive analyses for each survey question, the two major themes derived from consideration of both questions as a whole are presented in sections 3.1 and 3.2 with corresponding subsections that describe advice meant for fluent speakers and for PWS. Readers may refer to Table 1 for an overview of major themes that includes specific communication strategies participants recommended for both PWS and fluent speakers. Participants' direct quotes are incorporated into the results in order to clarify and contextualize the observed themes.

Insert Table 1 Here

\subsection{Theme 1: Changes to Communication: Increased Effort and Modifying Communicative Style}

A major finding of the study was that both PWS and fluent speakers were encouraged to listen more attentively to each other and to change their style of communication as necessary. Here we present participants' advice to fluent speakers as they interact with PWS, followed by their advice to PWS.

\subsubsection{Communication Changes Required of Fluent Speakers}

Participants suggested that it is difficult to understand the speech of PWS. Accordingly, they reported that fluent speakers should put more effort into communicating with PWS, including listening more carefully or concentrating harder on the message of PWS. As one participant advised, fluent speakers should "slow down and take the time to listen. Watch facial and body gestures [of PWS] to understand what is being communicated." In general, participants thought it was better to listen carefully so that one did not have to ask PWS to repeat themselves, but that if the message is not understood it is preferable to ask for clarification rather than act as if the speaker was understood. Participants recommended engineering the communicative interaction so that PWS did not have to speak as much. For example, one participant wrote, "ask questions or have conversations where the exchanges are kept short so the stutterer is not left giving lengthy responses that highlight the [stuttering] problem." Similarly, participants indicated that fluent speakers can moderate the time allowed for PWS to speak. Some respondents thought it would be helpful to allow PWS more time to speak in conversation: "Talk slowly and let the person know by your actions that you are relaxed and are not in a hurry. They will feel more relaxed and will be able to get their words out better." Other participants thought it was most helpful to speak for PWS: "In dealing with the person who [stutters] here at work, I try to fill in the gaps in communication myself-allowing the person to feel more relaxed." In both instances, participants seemed to believe that fluent speakers should provide more time or take on more of the communicative burden in order to facilitate conversation with PWS.

\subsubsection{Communication Changes Required of PWS}

Participants recommended that PWS focus on and modify their communication style; however, the strategies they recommended were in some ways very different for PWS as compared to fluent speakers. Participants recommended that PWS talk more slowly and concisely to avoid disfluencies and to communicate more effectively with listeners. A number of participants also reported that PWS should compensate for their stuttering by engaging in communicative situations in which verbal fluency is not required. Thus, PWS were advised to use sign language, gestures, or body language to communicate, and to interact with others via email, text messaging, and other electronic forms of communication. Participants thought it best if PWS "stay away from key words that may set off the stuttering" and "avoid people who look like they might be in a hurry, as they might not be as patient." Verbal fluency and avoiding stuttering seemed to be at the crux of participants' recommendations to PWS as they communicate with fluent speakers, though making good eye contact and attempting to clarify when listeners do not understand one's speech were also noted as important. These findings seem to suggest that fluent speakers anticipate that PWS will communicate inefficiently during verbal communication and expect that breakdowns in communication will occur. Participants' responses also indicated that fluent speakers prefer PWS to be as fluent as possible, and that avoiding verbal communication is acceptable if fluent speech is not feasible.

\subsection{Theme 2: Importance of Managing Emotional Reactions to Stuttering}

The second theme that emerged from the data was that participants believed that both fluent speakers and PWS have adverse reactions to stuttering that should be managed for effective communication. As in the previous sections, 
participants' advice to fluent speakers is presented first, followed by their advice to PWS.

\subsubsection{Management of Emotions by Fluent Speakers}

Above all else, participants advised fluent speakers to be patient with PWS. Stuttering was perceived as causing PWS a large amount of emotional distress. For example, one participant wrote, "Just be patient and be compassionate for the [PWS]. They are having a difficult time and are very self-conscious about their problem." Other participants thought that listener impatience could make PWS more nervous and make the stuttering worse. In light of these beliefs, fluent speakers were also encouraged to "be obvious in being patient to help the stutterer not be nervous, discouraged or upset." Fluent speakers were perceived as being prone to frustration and impatience with PWS because "it can take a long time for [PWS] to say what they are trying to say." Thus, fluent speakers were encouraged to regulate their own (primarily negative) predispositions to stuttering and to help put PWS at ease. This advice to fluent speakers suggests that participants believe that fluent speakers have the ability to exacerbate both stuttering and negative feelings toward stuttering for PWS.

\subsubsection{Management of Emotions by PWS}

As with fluent speakers, patience was reported as an important quality for PWS to possess, the implication being that PWS often become frustrated with themselves or their listeners. Participants encouraged PWS to relax when speaking, as nervousness was seen as making stuttering worse and causing anxiety for listeners. "The people who stutter need to help [fluent listeners understand] that they stutter and to be patient with them," wrote one participant. "Those who do not stutter get uncomfortable when the person who stutters gets frustrated. If the person who stutters will help the non-stutterer relax, the conversation will be fine. Making others relax is the biggest step." In this context it PWS who have the responsibility to put their fluent conversational partners at ease. Interestingly, participants often recommended that PWS disclose to listeners that they have a stuttering problem. Acknowledging stuttering and asking for listeners' patience were considered worthwhile strategies because, to paraphrase one participant, explaining that one stutters might relieve preconceived notions about stuttering. Use of humor and having self-confidence were also recommended by participants, perhaps indicating that these qualities put fluent speakers at ease as they interact with PWS. In general, participants' responses in this regard indicated that fluent speakers experience anxiety and uncertainty as they interact with PWS, and are grateful when PWS are able to discuss their stuttering and give some instructions for how to interact with someone who stutters (such as requesting patience or more time to speak).

\section{Discussion}

The purpose of this study was to conduct an in-depth exploration of fluent speakers' beliefs about effective conversational strategies one should use with PWS. Thematic analysis of the data suggests that for most people, reactions to stuttering are comprised not only of outward speech behaviors, but cognitive and emotional responses as well. Specifically, fluent speakers tend to anticipate communicative breakdowns with PWS and attempt to prevent or manage these breakdowns by regulating their own emotional reactions to stuttering, engaging in active listening strategies, and/or taking control of speaking opportunities in order to minimize stuttering and embarrassment for PWS and fluent speakers. Similarly, PWS are often advised by fluent speakers to manage their emotions, to put fluent speakers at ease, and to engage in avoidance behaviors such as gesturing and writing instead of verbal communication if speech fluency cannot be achieved.

The results of these studies suggest that fluent speakers can provide a rationale for their thoughts on how PWS and fluent speakers should engage each other in conversation. This rationale appears to be derived from complex metalinguistic, paralinguistic, and even kinesic considerations, as fluent speakers reported that decisions about communicative interactions took into account such factors as how long to hold the conversation, who should carry the conversational load, word choice, tone of voice, and use of gestures and body language. Such considerations belie the complexity of stuttering, which is, on the surface, a simple disruption of speech fluency which need not engender cognitive and emotional arousal in PWS or fluent speakers, but seems to do so anyway.

In general, the themes of this study are consistent with those of an earlier study by the authors (Hughes et al., 2010b). Both studies found that typically fluent speakers advocated respect for PWS and indicated a desire to help PWS feel comfortable when conversing. A minority of participants did not believe that any changes to communication should take place when conversing with PWS. Most participants, however, indicated that communication breakdowns caused by unintelligible or incomplete utterances by PWS were expected and should be prevented if possible. Employing active listening strategies and trying to reduce nervousness in both fluent speakers and PWS were advocated in order to prevent these breakdowns. Participants' responses, while thematically similar, did not always 
indicate agreement as to the best way to facilitate conversation between fluent speakers and PWS. For example, some participants indicated that finishing words or thoughts for PWS would be insulting and should be avoided to preserve the dignity of PWS; other participants felt that speaking on behalf of PWS was helpful and an act of kindness. Thus, it seems apparent that fluent speakers are well-meaning in their interactions with PWS, but that confusion among members of the general public exists with respect to the best way to facilitate conversations with PWS.

\section{Conclusion}

The metacognitive and metalinguistic strategies employed by people as they consider their conversational interactions with people who have communication disorders such as stuttering are interesting and worthy of further research, especially in experimental realms. The extent to which people actually deviate from their typical speaking and communication styles when communicating with people who have disordered communication is not known. In the case of stuttering, there are guidelines set forth by such organizations as The Stuttering Foundation (www.stutteringhelp.org) which delineate preferred conversational strategies for fluent speakers when interacting with PWS. Fluent speakers are advised to make eye contact, not interrupt or finish words, and avoid telling PWS to relax, take a deep breath, or slow down. Speaking in a manner that is relaxed and unhurried, but not so slow as to sound unnatural is also recommended (Stuttering Foundation of America, 2007). Little if any data has been collected about the extent to which people in the general public, as well as professionals who work with PWS in healthcare and educational settings, incorporate these practices when interacting with someone who stutters. The degree to which these conversational adaptations result in fewer communicative breakdowns and increased comfort during interactions between people with disordered communication and typical speakers is also unknown. Finally, a fruitful area of research may include an investigation of how English Language Learners are impacted by the presence of a communication disorder (see Wells Jensen, Hughes, and Daniels, 2008, for a review) and how language and linguistics teachers understand and cope with stuttering and other communication disorders in their classrooms.

\section{References}

Bennett, E. (2006). Working with people who stutter: A lifespan approach. Upper Saddle River, NJ: Pearson.

Bloodstein, O. \& Bernstein Ratner, N. (2007). A handbook on stuttering $\left(6^{\text {th }}\right.$ ed.). San Diego, CA: Singular.

Creswell, J.W. (2007). Qualitative inquiry and research design: Choosing among five traditions $\left(2^{\text {nd }}\right.$ ed.). Thousand Oaks, CA: Sage.

Cuddy, A.J.C., Fiske, S.T., \& Glick, P. (2008). Warmth and competence as universal dimensions of social perception: The stereotype content model and the BIAS map. Advances in Experimental Social Psychology, 40, 61-150. http://dx.doi.org/10.1016\%2FS0065-2601\%2807\%2900002-0

Guitar, B. (2006). Stuttering: An integrated approach to its nature and treatment. Baltimore, MD: Lippincott Williams \& Wilkins.

Guntupalli, V.K., Kalinowski, J., Nanjundeswaran, C., Saltuklaroglu, T., \& Everhart, D.E. (2006). Psychophysiological responses of adults who do not stutter while listening to stuttering. International Journal of Psychophysiology, 62, 1-8. http://dx.doi.org/10.1016/j.ijpsycho.2005.11.001

Ham, R.E. (1990). What is stuttering: Variations and stereotypes. Journal of Fluency Disorders, 15, 259-273. http://dx.doi.org/10.1016/0094-730X(90)90041-P

Hulit, L.M., \& Wirtz, L. (1994). The association of attitudes toward stuttering with selected variables. Journal of fluency disorders, 19, 247-267. http://dx.doi.org/10.1016/0094-730X(94)90003-5

Hughes, S., Gabel, R., \& Irani, F. (2010b). Fluent speakers' advice for communicating with people who stutter: The concept of mutual help and its effects on successful stuttering management. In E.L. Simon (Ed.), Psychology of stereotypes (pp. 1-46). Hauppauge, NY: Nova Publishers.

Hughes, S., Gabel, R., Irani, F., \& Schlagheck, A. (2010a). University students' explanations for their descriptions of people who stutter: An exploratory mixed model study. Journal of Fluency Disorders, 35, 280-298. http://dx.doi.org/10.1016/j.jfludis.2010.05.006

Kalinowski, J., Stuart, A., \& Armson, J. (1996). Perceptions of stutterers and nonstutterers during speaking and nonspeaking situations. American Journal of Speech-Language Pathology, 5, 61-67.

Lass, N.J., Ruscello, D.M., Schmitt, J.F., Pannbacker, M.D., Orlando, M.B., et al. (1992). Teachers' perceptions of stutterers. Journal of Language, Speech, and Hearing Services in Schools, 23, 78-81. 
Maxwell, J.A. (2005). Qualitative research design: An interactive approach. ( ${ }^{\text {nd }}$ ed.). Thousand Oaks, CA: Sage.

Panico, J., Healey, E.C., Brouwer, K., \& Susca, M. (2005). Listener perceptions of stuttering across two presentation modes: A quantitative and qualitative approach. Journal of Fluency Disorders, 30, 65-85. http://dx.doi.org/10.1016/j.jfludis.2005.01.003

Perkins, W.H., Kent, R.D., \& Curlee, R.F. (1991). A theory of neuropsycholinguistic function in stuttering. Journal of Speech and Hearing Research, 34, 734-752.

Stuttering Foundation of America. (2007). Tips for speaking with someone who stutters. Retrieved May 10, 2012 from http://www.stutteringhelp.org/Default.aspx?tabid=538

Swartz, E., Gabel, R., \& Irani, F. (2009). Speech language pathologists' attitudes toward people who stutter. Canadian Journal of Speech Language Pathology and Audiology, 33, 99-105.

Wells-Jensen, S., Hughes, S., \& Daniels, D. (2008). What classroom language teachers should know about communication disorders. Asian Quarterly: An International Journal of Contemporary Issues, 6, 9-32.

White, P.A., \& Collins, S.R.C. (1984). Stereotype formation by inference: A possible explanation for the "stutterer" stereotype. Journal of Speech and Hearing Research, 27, 567-570.

Yairi, E., \& Ambrose, N.G. (2005). Early childhood stuttering: For clinicians by clinicians. Austin, TX: Pro-Ed.

Table 1. Fluent Speakers' Recommendations for Communicating with PWS

\begin{tabular}{|c|c|}
\hline \multicolumn{2}{|l|}{ Theme 1: Changes to Communication } \\
\hline $\begin{array}{l}\text { Fluent speakers should: } \\
\text { - Concentrate harder } \\
\text { - Listen more attentively } \\
\text { - Keep conversations short } \\
\text { - Fill in words/thoughts for PWS }\end{array}$ & $\begin{array}{l}\text { People who stutter should: } \\
\text { - Focus on conversation } \\
\text { - Think before speaking } \\
\text { - Talk more slowly } \\
\text { - Avoid problematic words } \\
\text { - Use gestures, sign language, or body language } \\
\text { - Communicate via email, text, or writing }\end{array}$ \\
\hline \multicolumn{2}{|l|}{ Theme 2: Management of Emotions } \\
\hline $\begin{array}{l}\text { Fluent speakers should: } \\
\text { - Be patient } \\
\text { - Relax and remain calm }\end{array}$ & $\begin{array}{l}\text { People who stutter should: } \\
\text { - Be patient } \\
\text { - Relax and remain calm } \\
\text { - Acknowledge stuttering to put listeners at ease } \\
\text { - Have a sense of humor } \\
\text { - Be confident }\end{array}$ \\
\hline
\end{tabular}

Conversational strategies recommended for fluent speakers and PWS arranged by theme. 